\title{
Awareness Towards Fixed Orthodontic Treatment Among High School Students in Perambur - A Survey
}

\author{
B.Vivek Babu ${ }^{1}$ and Dhanraj Ganapathy ${ }^{2}$ \\ ${ }^{1}$ Saveetha Dental College, Saveetha Institute of Medical and Technical \\ Sciences Saveetha University. Chennai 600077, India \\ ${ }^{2}$ Professor \& HOD, Department of Prosthodontics, Saveetha Dental College, \\ Saveetha Institute of Medical and Technical Sciences Saveetha University. \\ Chennai 600077, India
}

\section{ABSTRACT}

Facial appearance plays a major role in all stages of human life which has got a great impact during pre-adolescent and adolescent phases. Malocclusion can conciliate the oral health tissues and can lead to social and psychological problems. Hence an investigation of the malocclusion status in growing children to intercept the same is required. The aim of this study is to survey the awareness of Fixed orthodontic treatment among school children in perambur. The objective of this study is to survey the school students about their awareness on fixed orthodontic treatment. The study was conducted among 100 law college students studying at Saveetha Law College in Chennai. A questionnaire was prepared consisting of 11 questions, and it was distributed to each of them, and they were evaluated individually. The results of the study were statistically analyzed both quantitatively and qualitatively through software called SPSS by IBM. Chi-Square analysis was also done. From the collected data it is evident that the female population was more $52.0 \%$. Many of them didn't know about fixed orthodontic treatment of 55.0\% of the population. $62.0 \%$ of them said their teeths are properly arranged. 57.0\% of them responded to the fact that they didn't have any kind of abnormalities in their teeth. 53.0\% of them knew that irregularly arranged teeth can be corrected through treatment. 36.36\% of them know that oral habits could lead to irregular arrangement of teeth. $60.0 \%$ of them knew that flossing, using mouth and proper brushing techniques will help in maintaining oral hygiene during orthodontic treatment. High school children exhibited more awareness towards orthodontic treatment.

\section{KEY WORDS: MALOCCLUSION; HIGH SCHOOL; PERAMBUR; FIXED ORTHODONTIC TREATMENT; KNOWLEDGE.}

\section{INTRODUCTION}

In 1922, the British Society for the Study of Orthodontics has defined the specialty as "Orthodontics" includes the study of growth and development of jaws and face,

\section{ARTICLE INFORMATION}

*Corresponding Author: dhanraj@saveetha.com

Received 27th July 2020 Accepted after revision 24th Sep 2020

Print ISSN: 0974-6455 Online ISSN: 2321-4007 CODEN: BBRCBA

Thomson Reuters ISI Web of Science Clarivate Analytics USA and Crossref Indexed Journal

\section{Clarivate
Analytics}

NAAS Journal Score 2020 (4.31) SJIF: 2020 (7.728)

A Society of Science and Nature Publication,

Bhopal India 2020. All rights reserved.

Online Contents Available at: http//www.bbrc.in/

Doi: http://dx.doi.org/10.21786/bbrc/13.8/171 particularly, and body generally as influencing position of teeth; study of action and reaction of internal and external influences on the development; and prevention and correction of arrested and perverted development.

Various factors such as adverse oral habits, anomalies in number of dentition, shape, and developmental position of teeth can cause malocclusion. Malocclusion affects periodontal health, causes dental caries and temporomandibular joint problems (Abu Alhaija, AlNimri and Al-Khateeb, 2005). Orthodontic treatment, more than improving the quality-of-life, can bring physical, psychological, and social changes (Feldmann et al., 2007). The major benefits of orthodontic treatment 
are to improve the physical function, prevention of tissue damage, and correction of esthetic components (Kaur, 2009).

A functional appliance is a removable or fixed appliance that alters the posture of the mandible and transmits the forces created by the resulting stretch of Research Article the muscles and soft tissues and by the change of the neuromuscular environment to the dental and skeletal tissues to produce movement of teeth and modification of growth (Marsico et al., 2011). Oral health will have an effect on the overall health and well-being of humans. In several nations, massive numbers of young aged teams square measure unaware concerning the causes, prevalence, and hindrance of most oral diseases (Siddegowda, 2015). Facial appearance plays a major role in all stages of human life which has got a great impact during pre-adolescent and adolescent phases. This is because they develop increased self-consciousness to their appearance. They harbour the belief that others are concerned with their looks as they themselves are. This increased self-awareness leads them to be more concerned about their health. Health is multifactorial and is an inseparable part of general health (Choi et al., 2015). Oral health knowledge and awareness are considered to be an essential pre-requisite for health-related behaviour (Wright, 1982).

Moreover, the treatment of disorder reduces the suffering among the patient and social embracement. Thus, it becomes highly important for us to identify the awareness of fixed orthodontic treatment among the school students in perambur so that they can prevent further malocclusion and cause further complications and moreover its their esthetic appearance and confidence that plays an important role for a high school going children in perambur. Previously our department has published extensive research on various aspects of prosthetic dentistry ('Evaluation of Corrosive Behavior of Four Nickel-chromium Alloys in Artificial Saliva by Cyclic Polarization Test:An in vitro Study', 2017; Ganapathy, Kannan and Venugopalan, 2017; Jain, 2017a, 2017b; Ranganathan, Ganapathy and Jain, 2017; Ariga et al., 2018; Gupta, Ariga and Deogade, 2018; Anbu et al., 2019; Ashok and Ganapathy, 2019; Duraisamy et al., 2019; Varghese, Ramesh and Veeraiyan, 2019), this vast research experience has inspired us to research the awareness of Fixed orthodontic treatment among school children in perambur.

\section{MATERIAL AND METHODS}

This is a cross sectional survey study where the study population is randomly chosen. The study was conducted among 100 high school going students in Perambur, Chennai. A questionnaire was prepared consisting of 11 questions, and it was distributed to each of them and they were evaluated individually. The results of the study were statistically analyzed both quantitatively and qualitatively. The data was collected during the time period of June 2019 to March 2020 were reviewed and collected data was statistically analysed with the help of SPSS by IBM and tables and graphs well plotted.

\section{RESULT AND DISCUSSION}

This study was mainly conducted to acknowledge the knowledge of high school students in perambur about fixed orthodontic treatment. The results were given in percentage for each question asked to the individual. Out of the total population $52.0 \%$ of them were females and $48.0 \%$ of them were males (Figure 1)

Figure 1: Shows a pie diagram representing gender prevalence, out of the total population $52.0 \%$ of them were females (Blue) and 48.0\% of them were males (Red).

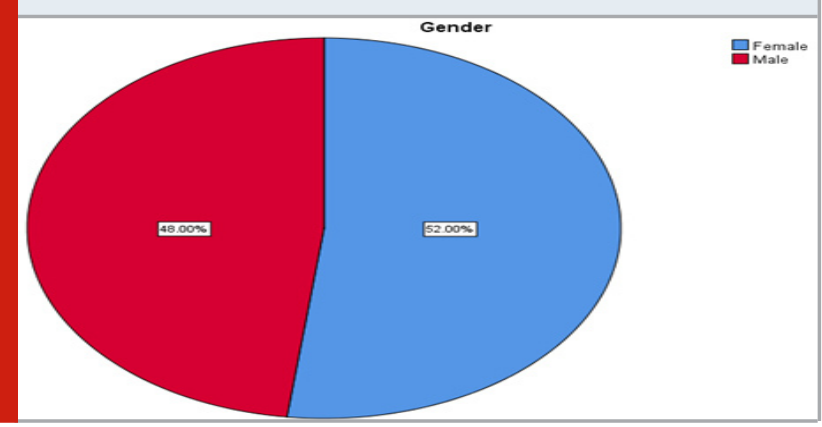

$55.0 \%$ of them didn't know about fixed orthodontic treatment and $45.0 \%$ of them knew about the fixed orthodontic treatment. (Figure 2).62.0\% of them told their teeths are properly arranged and 38.0\% of them told their teeths are not properly arranged. (Figure 3).57.0\% of them responded to the fact that they didn't have any kind of abnormalities in their teeth and 30.0\% of them responded that they had crowding in their teeth and $13.0 \%$ of them felt that they had spacing between their teeth. (Figure 4).39.0\% of them saw people wearing braces, $34.0 \%$ of them were not sure and $27.0 \%$ of them didn't see people with braces. (Figure 5).53.0\% of them knew that irregularly arranged teeth can be corrected, $30.0 \%$ of them were not sure about the correction and $17.0 \%$ of them felt that they cannot be corrected.

Figure 2: Shows a pie diagram represents $55.0 \%$ of them didn't know about fixed orthodontic treatment (Blue) and $45.0 \%$ of them knew about the fixed orthodontic treatment (Red).

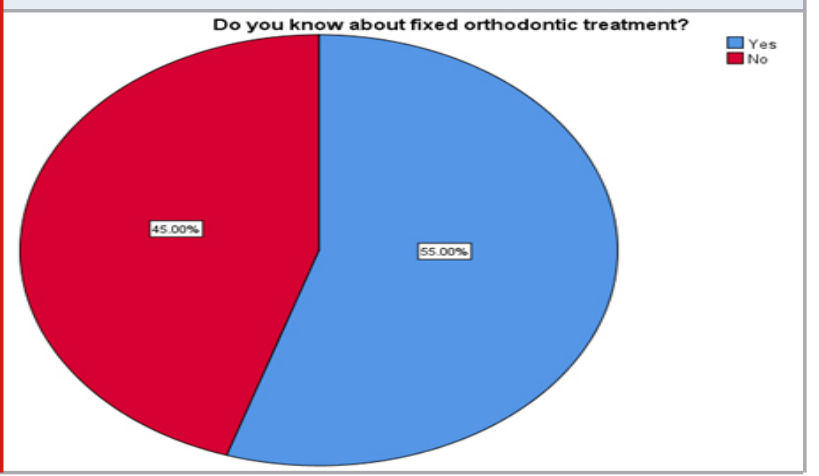


Figure 3: Shows a pie diagram represents $62.0 \%$ of them told their teeths are properly arranged and 38.0\% of them told their teeths are not properly arranged.

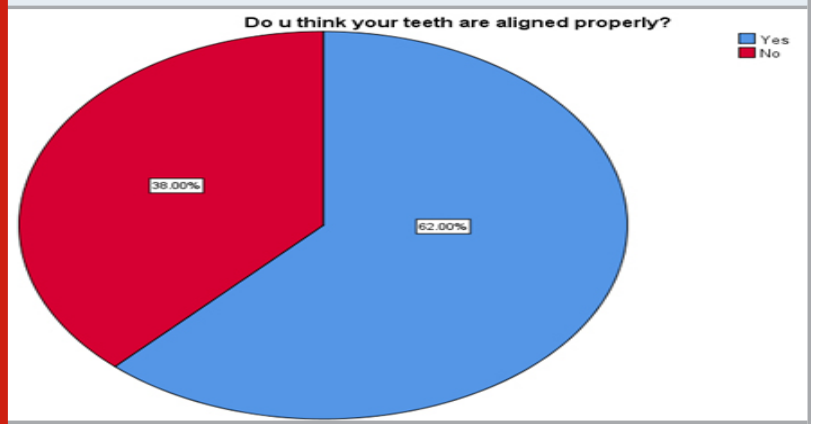

Figure 4: Shows a pie diagram represents $57.0 \%$ of them responded to the fact that they didn't have any kind of abnormalities in their teeth and $30.0 \%$ of them responded that they had crowding in their teeth and 13.0\% of them felt that they had spacing between their teeth.

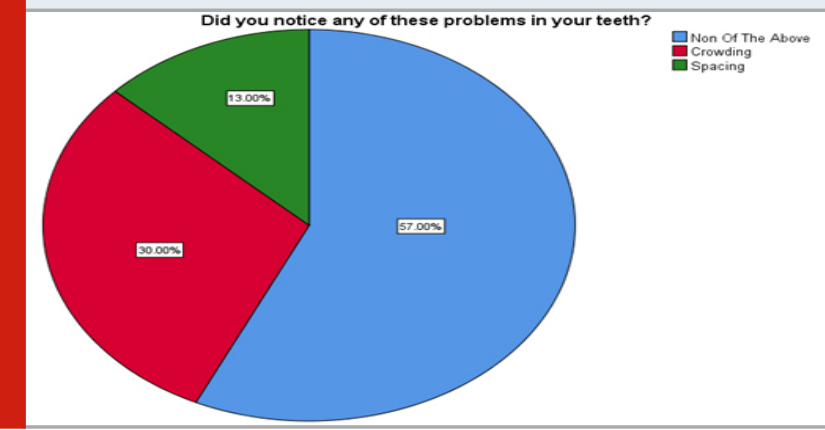

Figure 5: Shows a pie diagram represents $39.0 \%$ of them saw people wearing braces, $34.0 \%$ of them were not sure and $27.0 \%$ of them didn't see people with braces.

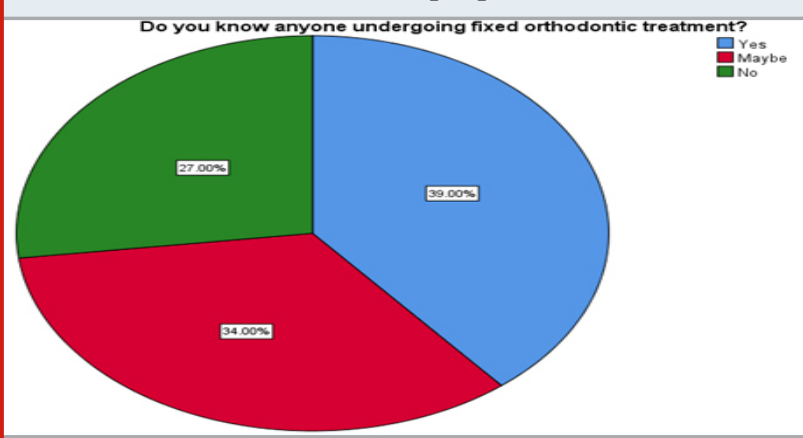

(Figure 6).36.36\% of the known oral habits could lead to irregular arrangement of teeth, 34.34\% of them didn't know that oral habits could lead to irregular arrangement of teeth and 29.29\% of them were not sure of the side effects of oral habits. (Figure 7).59.0\% of them have seen other people wearing braces and $41.0 \%$ of them didn't see any of them wearing braces. (Figure 8).44.0\% of them knew that the teeth can come back to the old position as it was before the treatment, 35.0\% of them didn't know that teeth can come back to the old position as it was before the treatment and $21.0 \%$ of them didn't know that treated teeth can come back to the old position as it was before the treatment. (Figure 9).50.0\% of them knew that they have to wear retainers after the treatment and 50.0\% of them didn't know that they have to wear retainers after the treatment.

Figure 6: Shows a pie diagram represents 53.0\% of them knew that irregularly arranged teeth can be corrected, $30.0 \%$ of them were not sure about the correction and $17.0 \%$ of them felt that they cannot be corrected.

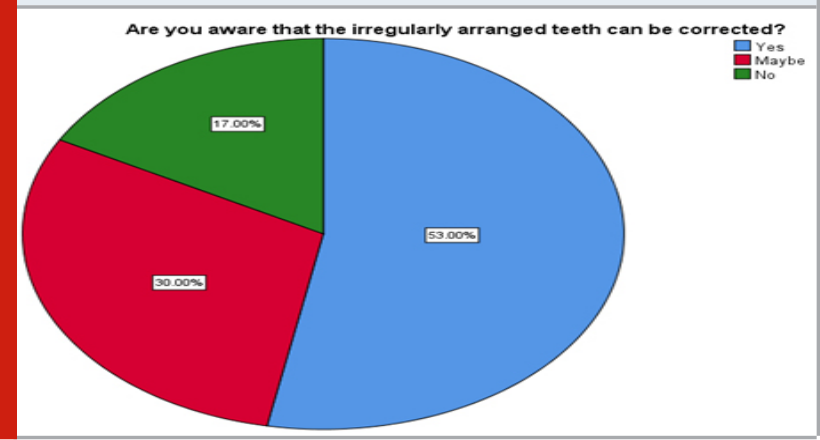

Figure 7: Shows a pie diagram represents $36.36 \%$ of the known oral habits could lead to irregular arrangement of teeth, 34.34\% of them didn't know that oral habits could lead to irregular arrangement of teeth and 29.29\% of them were not sure of the side effects of oral habits.

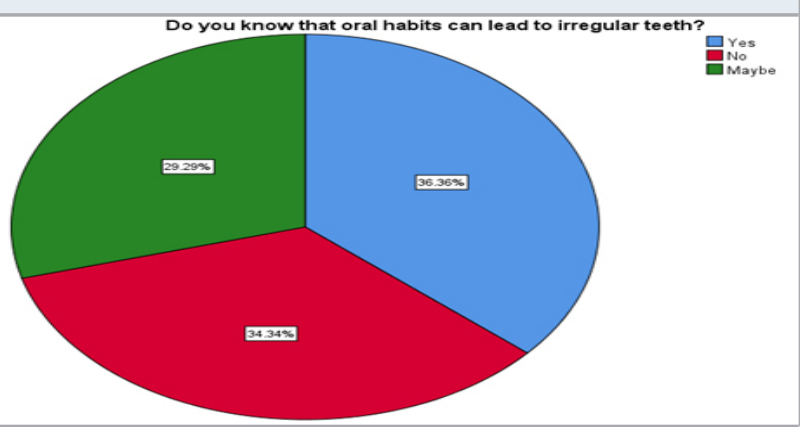

Figure 8: Shows a pie diagram represents $59.0 \%$ of them have seen other people wearing braces and $41.0 \%$ of them didn't see any of them wearing braces.

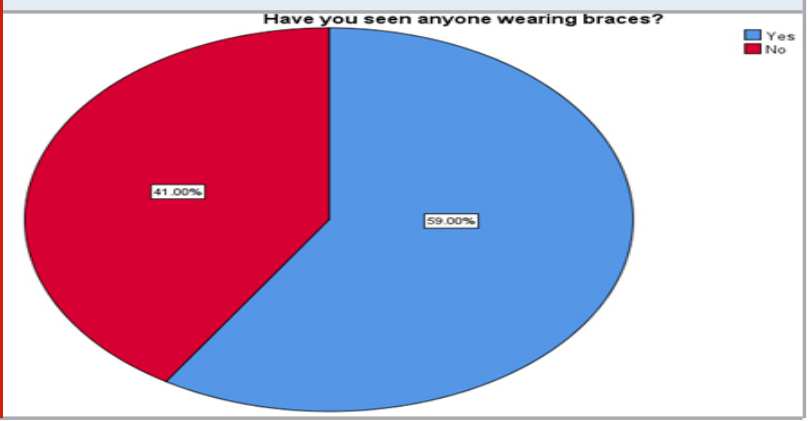

(Figure 10).43.0\% of them voted for 12 to 18 months, $29.0 \%$ of them voted for 6 months, 22.0\% of them voted for 6 to 12 months and 6.0\% of them thought it would take more than 18 months. (Figure 11).60.0\% of them knew that flossing, using mouth and proper brushing techniques will help in maintaining oral hygiene during orthodontic treatment. 22.0 of them 
thought using mouth was will help in maintaining oral hygiene during orthodontic treatment, $16.0 \%$ of them thought maintaining proper brushing techniques will help in maintaining oral hygiene during orthodontic treatment and 2.0\% of them knew that flossing will help in maintaining oral hygiene during orthodontic treatment. (Figure 12)

Figure 9: Shows a pie diagram represents $44.0 \%$ of them knew that the teeth can come back to the old position as it was before the treatment, $35.0 \%$ of them didn't know that teeth can come back to the old position as it was before the treatment and $21.0 \%$ of them didn't know that treated teeth can come back to the old position as it was before the treatment.

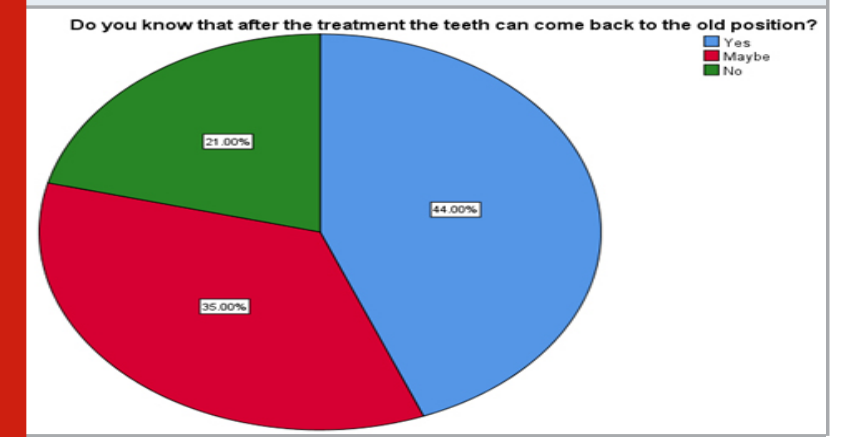

Figure 10: Shows a pie diagram represents 50.0\% of them knew that they have to wear retainers after the treatment and $50.0 \%$ of them didn't know that they have to wear retainers after the treatment.

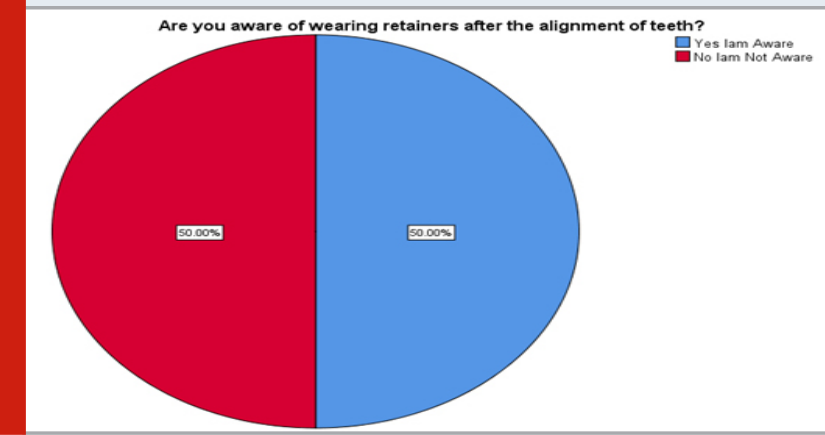

Figure 11: Shows a pie diagram represents $43.0 \%$ of them voted for 12 to 18 months, 29.0\% of them voted for 6 months, $22.0 \%$ of them voted for 6 to 12 months and $6.0 \%$ of them thought it would take more than 18 months.

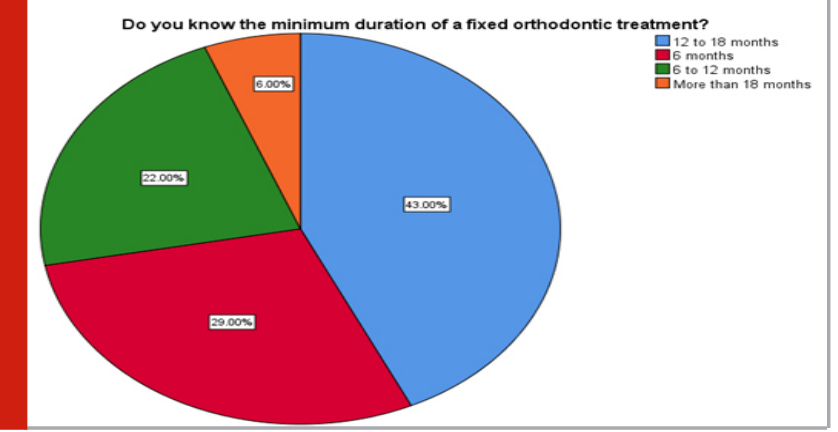

Figure 12: Shows a pie diagram represents $60.0 \%$ of them knew that flossing, using mouth and proper brushing techniques will help in maintaining oral hygiene during orthodontic treatment. 22.0 of them thought using mouth was will help in maintaining oral hygiene during orthodontic treatment, $\mathbf{1 6 . 0} \%$ of them thought maintaining proper brushing techniques will help in maintaining oral hygiene during orthodontic treatment and $2.0 \%$ of them knew that flossing will help in maintaining oral hygiene during orthodontic treatment.

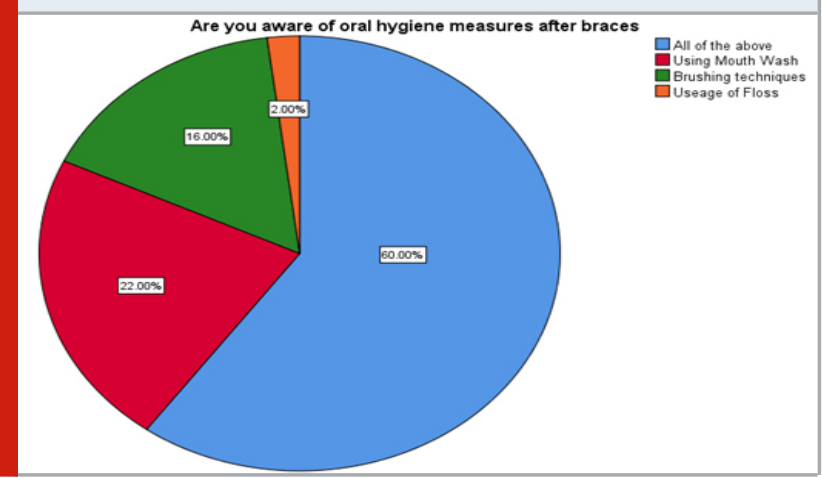

Self-awareness is a dynamic process, not a static phenomenon (Rochat, 2003). Attitudes and perceptions towards dental appearance differ among populations and among individuals (Vallittu, Vallittu and Lassila, 1996). Age-related changes in malocclusion concerns ideally should be studied longitudinally because with the progress in age, the awareness of malocclusion increases. The level of dental health knowledge, positive dental health attitude, and dental health behavior are interlinked and associated with the level of education and income as demonstrated by studies in the past (AlWahadni, Al-Omiri and Kawamura, 2004) (Kawamura, Iwamoto and Wright, 1997).

From the collected data it is evident that the female population was more by $52.0 \%$. Many of them didn't know about fixed orthodontic treatment of 55.0\% of the population, This is also proved by a study conducted by Siddegowda R 39.6\% of the were aware of orthodontics (Siddegowda, 2015). 62.0\% of them said their teeths are properly arranged this is supported by a study conducted by Shahul Hameed Faizee et,al; that 52.7\% of them were happy with the arrangement of their own teeth (Faizee et al., 2018). 57.0\% of them responded to the fact that they didn't have any kind of abnormalities in their teeth this is supported by a study conducted by Shahul Hameed Faizee et,al; that $52.7 \%$ of them were happy with the arrangement of their own teeth (Faizee et al., 2018).

$39.0 \%$ of them have seen people wearing braces. This is supported by the study conducted by Siddegowda $\mathrm{R} 76.4 \%$ of them have seen people wearing braces (Siddegowda, 2015). 53.0\% of them knew that irregularly arranged teeth can be corrected through treatment. $36.36 \%$ of them know that oral habits could lead to irregular arrangement of teeth This is supported by study done by (Siddegowda, 2015) 53.1\% of them are aware of 
the side effects of oral habits (Siddegowda, 2015). 43.0\% of them voted for 12 to 18 months This is evident from the study conducted by (Siddegowda, 2015) reveld 38.9\% of them were aware of the duration of the orthodontic treatment (Siddegowda, 2015). 60.0\% of them knew that flossing, using mouth and proper brushing techniques will help in maintaining oral hygiene during orthodontic treatment.

A study carried out in China in which $80 \%$ of females were not willing for treatment mainly due to the following reasons such as lack of information about orthodontic treatment and may have suffered from dental phobia; women who were single worried that the braces might lower their chances of social life; few worried about appearance and speech with braces; and some the cost, pain, and dental hygiene (Klages et al., 2005). There should be a proper knowledge about fixed orthodontic treatment and proper average cost of treatment and duration of treatment. There should be regular camps in order to make people aware of the need of treatment.

\section{CONCLUSION}

From our study we conclude that creating awareness is the first step of oral health education. In a society like ours where most people are not aware of the adverse effects of malocclusion and its consequences, the main reason behind this may be attributed to inadequate implementation of preventive oral health-care programs. High school children exhibited more awareness towards orthodontic treatment.

\section{ACKNOWLEDGEMENTS}

We acknowledge Saveetha Dental college for all the help and support.

Conflict of Interest: The authors declare no conflict of interest.

\section{REFERENCES}

Abu Alhaija, E. S. J., Al-Nimri, K. S. and Al-Khateeb, S. N. (2005) 'Self-perception of malocclusion among north Jordanian school children', European journal of orthodontics, 27(3), pp. 292-295.

Al-Wahadni, A. M., Al-Omiri, M. K. and Kawamura, M. (2004) 'Differences in self-reported oral health behavior between dental students and dental technology/dental hygiene students in Jordan', Journal of oral science, 46(3), pp. 191-197.

Anbu, R. T. et al. (2019) 'Comparison of the Efficacy of Three Different Bone Regeneration Materials: An Animal Study', European journal of dentistry, 13(1), pp. 22-28.

Ariga, P. et al. (2018) 'Determination of Correlation of Width of Maxillary Anterior Teeth using Extraoral and Intraoral Factors in Indian Population: A Systematic Review', World Journal of Dentistry, 9(1), pp. 68-75.
Ashok, V. and Ganapathy, D. (2019) 'A geometrical method to classify face forms', Journal of oral biology and craniofacial research, 9(3), pp. 232-235.

Choi, S.-H. et al. (2015) 'Impact of malocclusion and common oral diseases on oral health-related quality of life in young adults', American Journal of Orthodontics and Dentofacial Orthopedics, pp. 587-595. doi: 10.1016/j.ajodo.2014.12.025.

Duraisamy, R. et al. (2019) 'Compatibility of Nonoriginal Abutments With Implants: Evaluation of Microgap at the Implant-Abutment Interface, With Original and Nonoriginal Abutments', Implant dentistry, 28(3), pp. 289-295.

Evaluation of Corrosive Behavior of Four Nickelchromium Alloys in Artificial Saliva by Cyclic Polarization Test:An in vitro Study' (2017) World Journal of Dentistry, 8(6), pp. 477-482.

Faizee, S. H. et al. (2018) 'Awareness survey about the effects of malocclusion among young adults', Indian journal of dental research: official publication of Indian Society for Dental Research, 29(6), pp. 705-710.

Feldmann, I. et al. (2007) 'Reliability of a questionnaire assessing experiences of adolescents in orthodontic treatment', The Angle orthodontist, 77(2), pp. 311317.

Ganapathy, D. M., Kannan, A. and Venugopalan, S. (2017) 'Effect of Coated Surfaces influencing Screw Loosening in Implants: A Systematic Review and Meta-analysis', World Journal of Dentistry, 8(6), pp. 496-502.

Gupta, P., Ariga, P. and Deogade, S. C. (2018) 'Effect of Monopoly-coating Agent on the Surface Roughness of a Tissue Conditioner Subjected to Cleansing and Disinfection: A Contact Profilometric Study', Contemporary clinical dentistry, 9(Suppl 1), pp. S122S126.

Jain, A. R. (2017a) 'Clinical and Functional Outcomes of Implant Prostheses in Fibula Free Flaps', World Journal of Dentistry, 8(3), pp. 171-176.

Jain, A. R. (2017b) 'Prevalence of Partial Edentulousness and Treatment needs in Rural Population of South India', World Journal of Dentistry, 8(3), pp. 213-217.

Kaur, B. (2009) 'Evaluation of oral health awareness in parents of preschool children', Indian journal of dental research: official publication of Indian Society for Dental Research, 20(4), pp. 463-465.

Kawamura, M., Iwamoto, Y. and Wright, F. A. (1997) 'A comparison of self-reported dental health attitudes and behavior between selected Japanese and Australian students', Journal of dental education, 61(4), pp. 354-360.

Klages, U. et al. (2005) 'Dental esthetics, orthodontic treatment, and oral-health attitudes in young 
adults', American Journal of Orthodontics and Dentofacial Orthopedics, pp. 442-449. doi: 10.1016/j. ajodo.2004.05.023.

Marsico, E. et al. (2011) 'Effectiveness of orthodontic treatment with functional appliances on mandibular growth in the short term', American journal of orthodontics and dentofacial orthopedics: official publication of the American Association of Orthodontists, its constituent societies, and the American Board of Orthodontics, 139(1), pp. 24-36.

Ranganathan, H., Ganapathy, D. M. and Jain, A. R. (2017) 'Cervical and Incisal Marginal Discrepancy in Ceramic Laminate Veneering Materials: A SEM Analysis', Contemporary clinical dentistry, 8(2), pp. 272-278.

Rochat, P. (2003) 'Five levels of self-awareness as they unfold early in life', Consciousness and cognition, 12(4), pp. 717-731.
Siddegowda, R. (2015) 'An Epidemiological Survey on the Awareness towards Orthodontic Treatment among Middle School and High School Children of Karnataka State', Journal of Cell Science \&t Therapy. doi: 10.4172/2157-7013.1000213.

Vallittu, P. K., Vallittu, A. S. J. and Lassila, V. P. (1996) 'Dental aesthetics - a survey of attitudes in different groups of patients', Journal of Dentistry, pp. 335-338. doi: 10.1016/0300-5712(95)00079-8.

Varghese, S. S., Ramesh, A. and Veeraiyan, D. N. (2019) 'Blended Module-Based Teaching in Biostatistics and Research Methodology: A Retrospective Study with Postgraduate Dental Students', Journal of dental education, 83(4), pp. 445-450.

Wright, F. A. C. (1982) 'Children's perception of vulnerability to illness and dental disease', Community Dentistry and Oral Epidemiology, pp. 29-32. doi: 10.1111/j.1600-0528.1982.tb00356.x. 